Chapter 7

\title{
Radiation Therapy with a Simultaneous Integrated Boost
}

Despina Katsochi

Additional information is available at the end of the chapter

http://dx.doi.org/10.5772/67326

\begin{abstract}
Radiotherapy has an established role in the treatment of cancer and represents a definitive, less invasive approach for various cancer types. Its main aim is to deliver the maximum dose to the tumor with minimal toxicity on neighboring healthy tissues. Therefore, the precise determination of the target and its spatial relation to critical surrounding organs is of main importance. New imaging modalities such as the CT, MRI, and PET/CT offer more anatomical detail and facilitate the accurate delineation of the target volume and the organs at risk. The recent advances in 3D-CRT and IMRT radiation techniques offer high accuracy in tumor targeting and ensure safe dose escalation. Moreover, the introduction of IGRT offers the opportunity to safely apply a supplementary dose to the macroscopic tumor. In trials conducted, a simultaneous integrated boost (SIB) has proved to be feasible in various cancer localizations, to safely increase the total delivered dose, shorten the total treatment time and results in increased tumor control while keeping the side effects low at the same time. However, more trials need to be conducted to establish an acceptable protocol.
\end{abstract}

Keywords: radiation therapy, simultaneous integrated boost, fractionation, radiation dose escalation, image guided radiotherapy

\section{Introduction}

Radiation therapy is the core treatment strategy with curative intent and organ preservation for many inoperable cancer types. The main aim of radiation therapy is the local control of the tumor.

With open field conventional 2D RT, both healthy tissue and tumors are irradiated with a similar dose per fraction of 1.8-2 Gy. Now, the 3D-CRT is the new standardized procedure. The target volumes are defined on CT or PET-CT or other high-definition imaging such as 
the MRI. During the treatment planning, a 3-D projection of the area of interest provides the opportunity to match the high-dose radiation region to the target volume while minimizing the radiation dose to the surrounding healthy tissue. More refined radiation techniques, which lead to enhanced conformity, can be performed with the use of these generation machines. 3-D techniques have given way to IMRT or volumetric modulated arc therapy (V-MAT) [1-4].

High conformity is generally accepted as a way to reduce toxicity and allows dose escalation to produce better results and long-term tumor control. This is only possible through IGRT, which involves real-time imaging of the treatment target and normal organs during each treatment, in order to avoid uncertainty about patient positioning and tumor targeting and to also reduce the irradiated volumes without missing any of the targets [5].

Trials have investigated different fractionation schedules to also increase local control, which has become of high importance in clinical oncology patient management. Randomized clinical trials have established equivalent outcomes between radical surgery and organ-preservation treatment with an RT backbone for appropriately selected patients.

The radiation oncologist's main concern is local recurrence after definitive radiation therapy. The combined chemo-radiation protocols have led to the increased tumor control and survival rates, but the results have remained unchanged for a long time. All eyes are now on radiation therapy for a more targeted improvement of local tumor control and diminishment of the odds of local recurrence [6].

The newly developed approach of applying different radiation doses to different areas in one single session is called SIB or simultaneous integrated boost-intensity-modulated radiotherapy (SIB-IMRT). By increasing the dose per fraction focally to the tumor itself while maintaining lower dose to the elective areas of interest, a more accurate dose distribution can be achieved, in order to improve local tumor control without putting the neighboring organs at risk. The advances, improvements and clinical usage of this technique will be expanded in full detail [7].

\section{Simultaneous integrated boost-radiation therapy strategy and procedure}

The radiation therapy strategy is an evidence-based treatment, personalized to the particular needs of each individual patient. The 3D-CRT is the minimum standard for the delivery of a radiation dose that conforms to the target volume and controls the exposure to surrounding tissue (Figure 1). The evolution of the 3D-CRT is the IMRT technique. It optimizes the radiation intensity distribution within each beam in order to achieve a higher rate of conformity and target coverage especially for irregularly shaped tumors, using nonuniform radiation beam intensities to maximize the delivery of radiation to the planned target volume while minimizing irradiation of normal tissue outside the target. It requires a precise definition of anatomy, a treatment planning system that can calculate the dose in three dimensions, and a treatment device that can deliver the specified dose. Randomized studies demonstrate reduced side effects with IMRT (particularly that of xerostomia in patients with head and neck tumors) in comparison with older 3D-CRT techniques even in the setting of concurrent chemotherapy. 
The delivery of each dose to the tumor has become much faster with the introduction of the VMAT where the gantry moves around the patient as the beam is being modulated (Figure 2). Typically, IMRT plans require 20-25 min for delivery of the daily treatment while a VMAT plan can now be delivered in approximately $3-5 \mathrm{~min}$ (approximately $1.5 \mathrm{~min}$ per gantry rotational arc), which is easier on patients (Figure 3) [8-10].

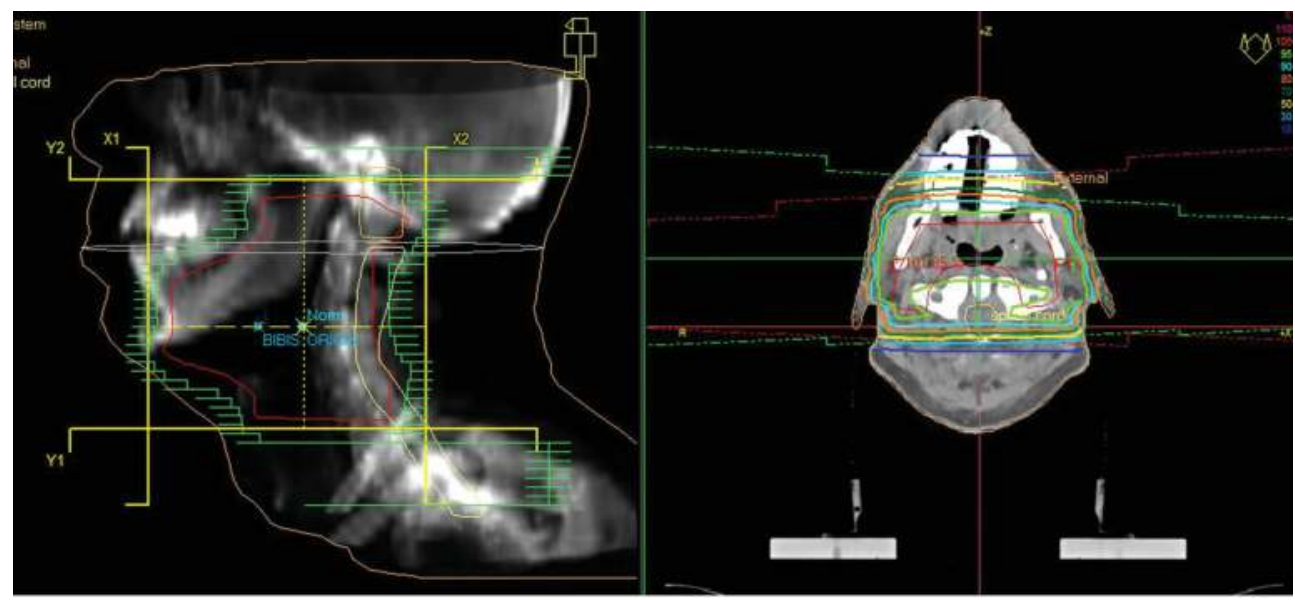

Figure 1. 3D-CRT RT with multileaf collimator shielding.

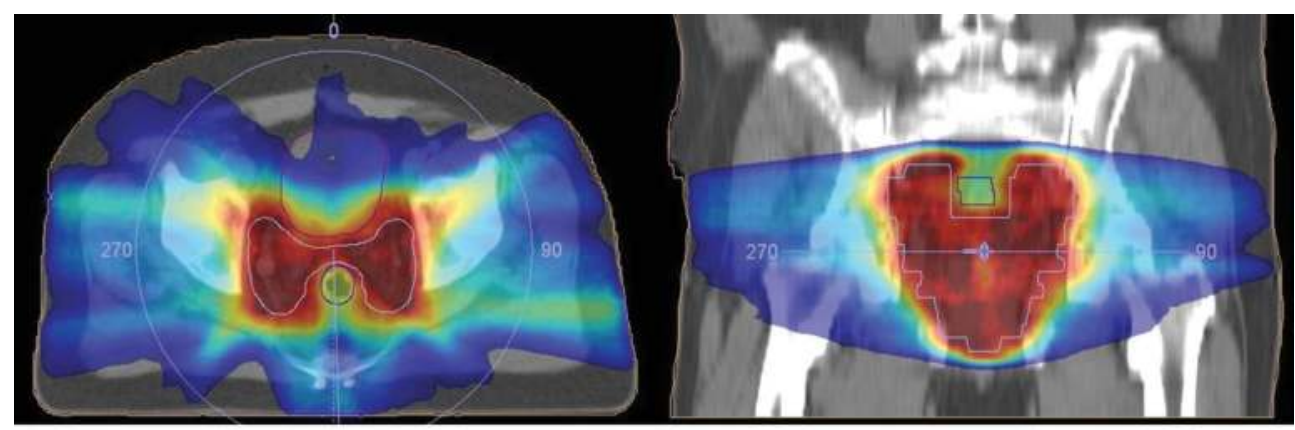

Figure 2. IMRT: Gradient dose distribution is achieved in the different parts of the target volume, and the surrounding healthy tissue is less exposed to the total radiation dose.

Treatment planning is the most important procedure. Target delineation is the main concern of the radiation oncologist. The definition of the extension of the infiltrated tissue is often an interdisciplinary procedure where the surgeon, pathologist, radiologist and radiation oncologist have to collaborate in order to decide on the most appropriate treatment plan. The precise determination of the target and its spatial relation to critical surrounding organs is of main importance. The reference imaging modality for RT treatment planning is the CT with which we can 
fuse additional medical images (MRI PET/CT scans) for accurate treatment planning, dosimetric calculations and ensure safe dose escalation. The PET/CT images can change gross tumor volume (GTV) delineation in 35-60\% of patients treated and show a better treatment outcome (31 months vs. 16 months) and can increase the 1-year survival rate from 8 to $17 \%$ (Figure 4) [11-15].

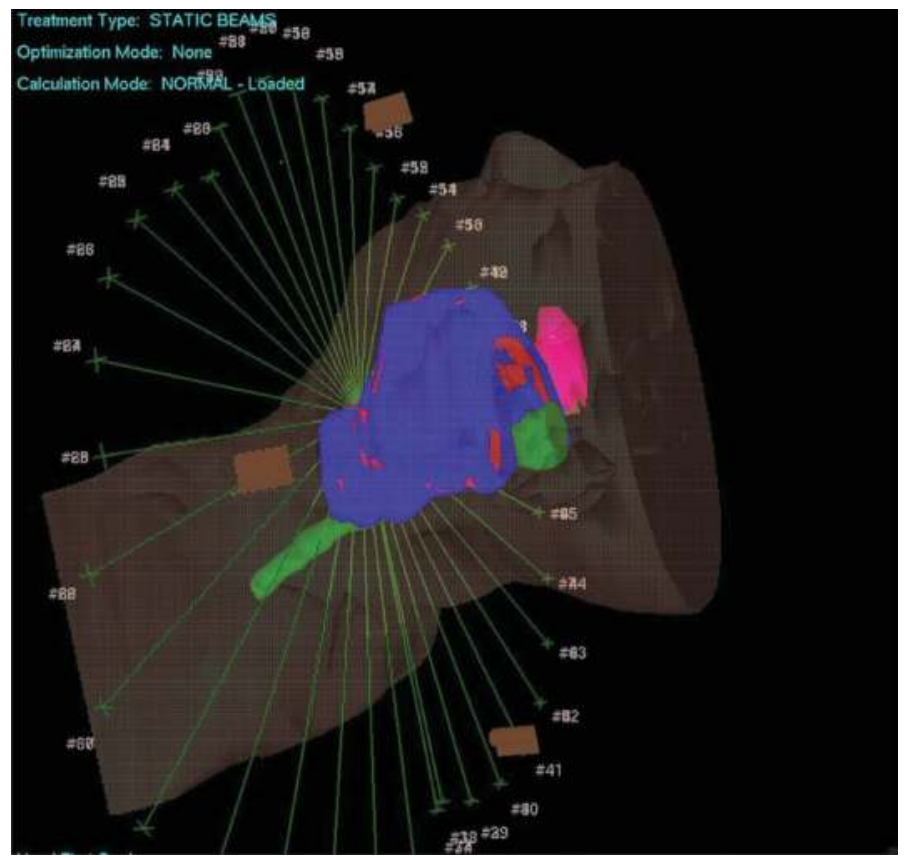

Figure 3. VMAT where the gantry moves around the patient as the beam is being modulated.

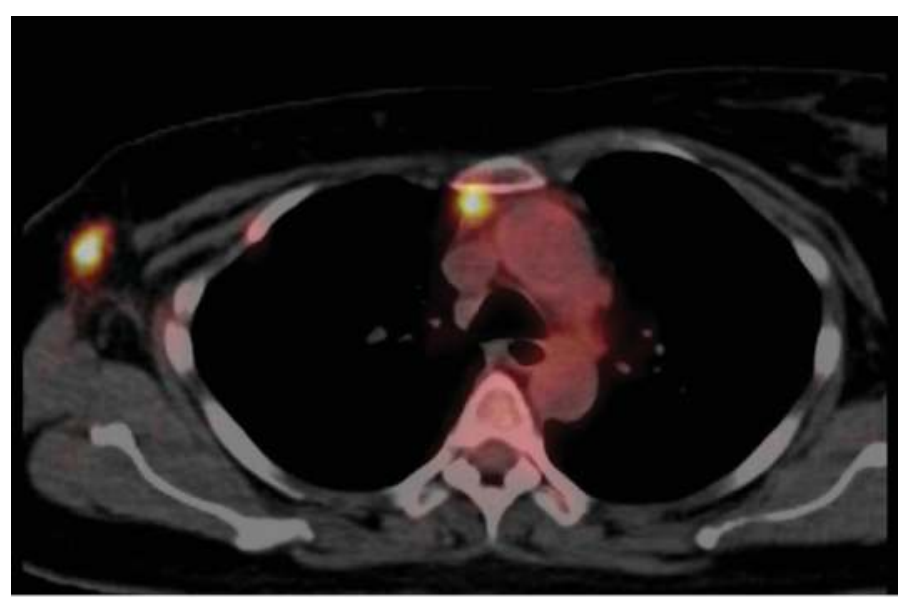

Figure 4. PET/CT gives information about the metabolic tumor activity. 
For accurate 3D-CRT and IMRT delivery, every day patient set up and verification systems are required, i.e., CBCT scanners, which produce 3-D images of the treatment area (Figure 5) [10, 11].

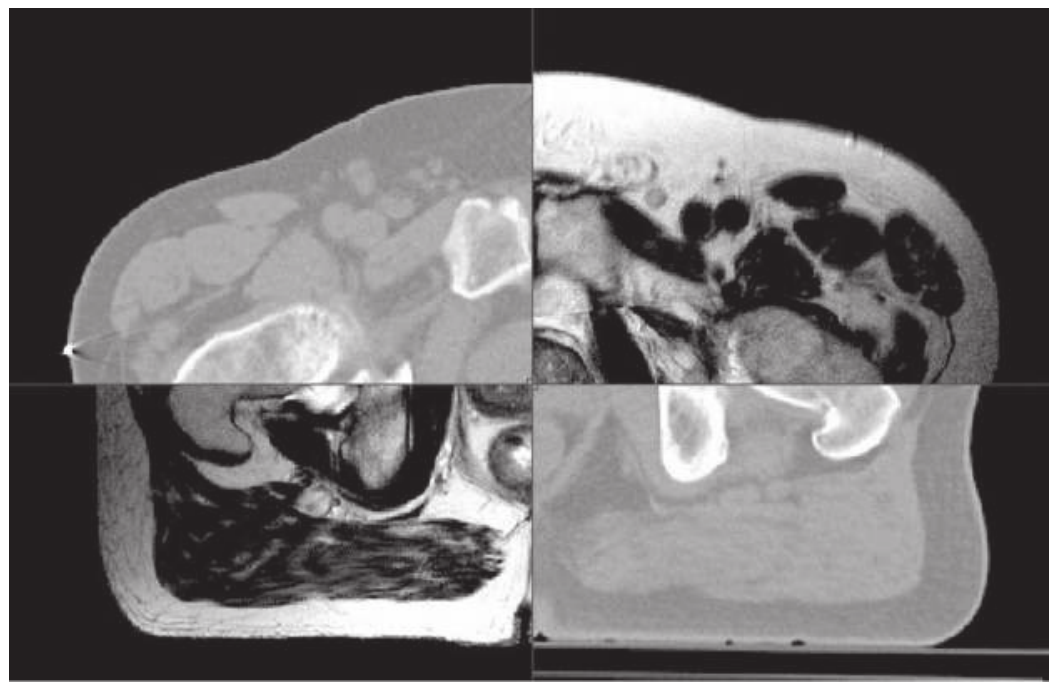

Figure 5. IGRT real-time imaging of the treatment area fused with the computer tomography image used for the planning.

According to ICRU-83, the GTV represents the palpable or visible (on imaging) tumor, whereas the so-called clinical target volume (CTV) is an additional volume with a certain probability of microscopic (subclinical) malignant disease. The irradiated planning target volume (PTV) is a geometrical concept. The PTV is defined according to the ICRU 62 report and includes GTV, CTV and takes into account the internal organ motion and set up errors $[16,17]$.

In the past, radiation therapy was applied using a shrinking field approach or sequential boost, starting with large fields and shrinking gradually depending on the pre-planned total dose to each region. Inevitably, the high-risk target volume or GTV, the intermediate risk target volume or CTV and the low risk volume or PTV were exposed to different total doses, which have been delivered sequentially (SeqB-IMRT intensity-modulated radiotherapy sequential boost). This risk adaptive strategy now is modified to deliver a single efficient treatment plan with dose levels and intensities appropriate for each elected region. The SIB-IMRT is more conformal and potentially enables a slightly higher dose escalation to high-risk volumes compared to the SeqB-IMRT. Higher conformity in combination with smaller PTV allows 25\% RT dose escalation and increases the effectiveness of therapy. A dose escalation of $10 \mathrm{~Gy}$ to lung cancer patients treated with 3D-CRT is correlated with 36\% decrease in local failure rates [18-20].

The concomitant boost technique is a variant of accelerated fractionation, whereby the boost is delivered as a second daily fraction during the basic treatment course to reduce the total duration of treatment. The incorporation of boost at the same session of RT is the SIB, which involves the CTV with a prophylactic dose and the GTV with a curative dose. 
Simultaneous accelerated radiation therapy (SMART) boost technique initially was described by Butler in 1999 [21]. The GTV was treated with large fractions of $2.4 \mathrm{~Gy}$, while conventional fractions of 2 Gy were delivered to the PTV, which represent the regions at risk for microscopic disease up to a total dose of 60 and $50 \mathrm{~Gy}$, respectively. The total treatment time was moderately shortened than previously. The term "simultaneous integrated boost" was introduced later to define such treatment, delivering different doses per fraction in different target regions, by Mohan, 2000 [22]. The initial proposed dose delivery was either the conventional 2 Gy per fraction to the lower or intermediate dose volumes, thereby enabling a higher dose per fraction to be delivered to the GTV, with as much as $2.4 \mathrm{~Gy}$ for gross disease. The SIB technique offers the biological advantage of shortened treatment duration, i.e., 70 Gy over 6 weeks, which has been shown to significantly increase the loco-regional control compared to the same dose delivered in 7 weeks. According to the literature provided, an increase in the biological dose of $7.5 \%$ could be translated into an increase in loco-regional control in the order of $15 \%$. In this context, the gain resulting from an increase in the equivalent dose can be achieved without any further increase in late normal tissue complications compared to standard treatment. Only the normal tissues embedded in the tumor volume and thus included in the PTV will be irradiated with a dose per fraction similar to that of the tumor itself. Provided that the dose per fraction to the organs at risk is limited to a maximum of $2 \mathrm{~Gy}$ per fraction, this increase in dose intensity will be achievable without undue damage to normal tissue (Figure 6) [23, 24].

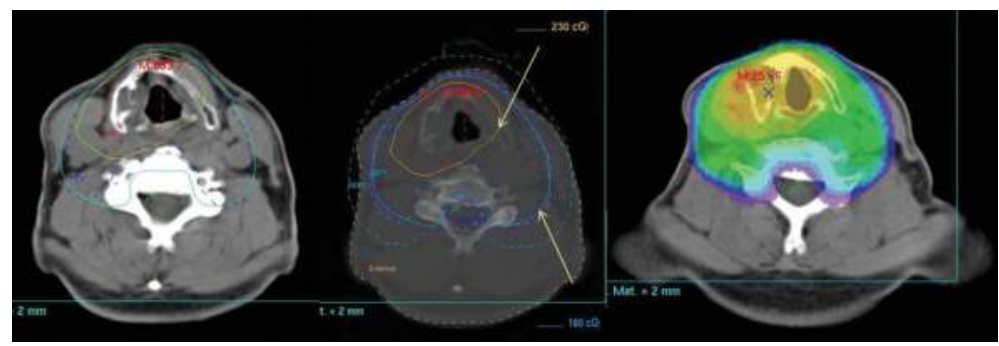

Figure 6. SIB-IMRT gradient dose distribution in the different parts of the target volume and the surrounding healthy issue in one single session.

In the following paragraphs, there are detailed examples of different cases where the SIB technique has been applied.

It is a fact that the treatment of head and neck cancers is influenced by fraction size, total dose and overall treatment time regarding the tumor control and toxicity. The total radiation dose has demonstrated a direct impact to the tumor response as well as to the acute or late adverse events.

The SIB-IMRT approach may be used to deliver a fraction size of 2.2 Gy to the boost volume and a fraction size of $1.8 \mathrm{~Gy}$ to the elective volume in the same treatment session. As a result, the high-risk volume is treated with fewer fractions compared to conventional protocols and leads to reduction in the overall treatment time (6 weeks compared to 7 weeks) (Figure 7). 


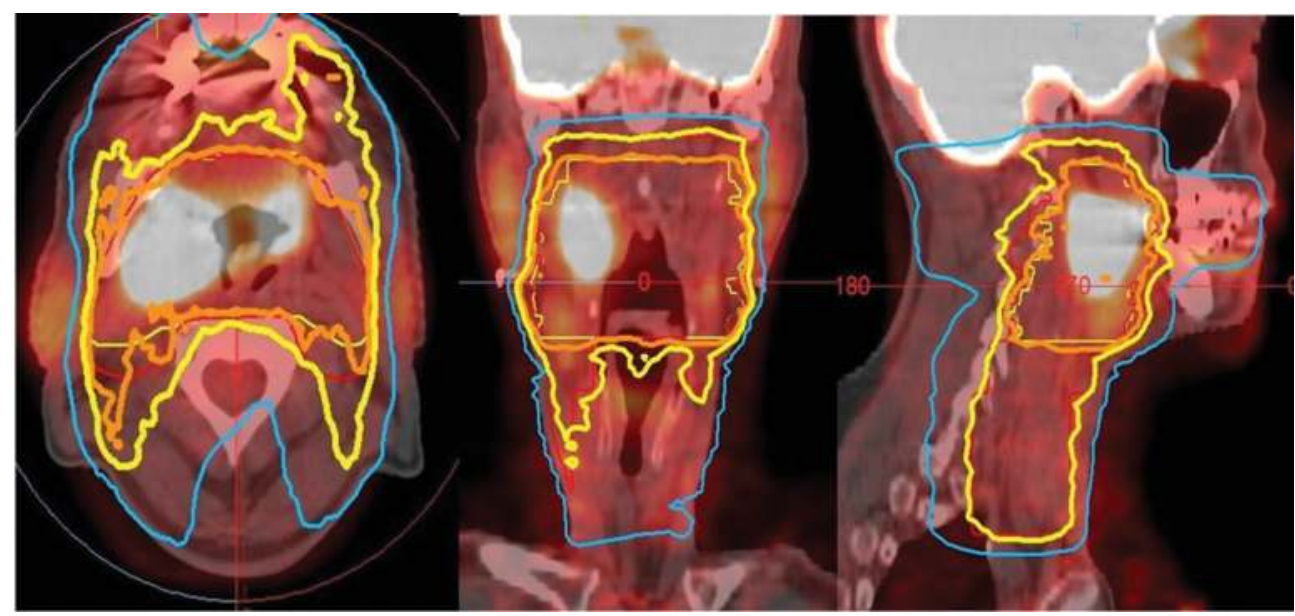

Figure 7. Head and neck tumor, metabolic image activity for better targeting of GTV gross tumor volume.

According to the RTOG H-0022 trial for oropharyngeal carcinomas SIB-IMRT in head and neck cancer, the use of 2.0, 2.11 or 2.2 Gy per session is highly effective and safe with respect to tumor response and tolerance. However, SIB with $2.2 \mathrm{~Gy}$ is not recommended for large tumors involving laryngeal structures [25-32].

Before the arrival of IMRT, the SeqB method was mostly used, within the 3D conformal irradiation technique to treat high-grade gliomas. With the SIB method, the dose per fraction to the PTV is lower when compared with the SEB, delivers an enhanced dose to the gross tumor volume and has a greater potential of sparing of organs at risk (Figure 8) [33-37].

Whole brain radiotherapy is the most common palliative treatment and has always been considered the standard treatment for patients with brain metastases. As opposed to surgery which was used in the past decades, today neurosurgical techniques such as radiosurgery have been combined with whole brain radiotherapy and have allowed for using more aggressive local treatment with the goal to increase local control probability and potentially overall survival. The literature reports a statistical advantage on overall survival probability in patients with a single brain metastasis treated with a combination of whole brain radiotherapy and radiosurgery compared with whole brain radiotherapy alone.

According to RTOG, the use of 20 Gy in five fractions to the WBRT can be considered an acceptable fractionation and is equivalent to $30 \mathrm{~Gy}$ in 2 weeks. Median survival (15-18 weeks) and overall response rates probability (75-80\% for symptom palliation) are similar. The SIB together with this hypofractionated schedule in WBRT (20 Gy in five fractions) (40 Gy in five fractions) has proven to be feasible. This schedule offers the advantage of shorter treatment time, which could be very useful in oligometastatic patients that need systemic therapy (Figure 9) [38-43]. 

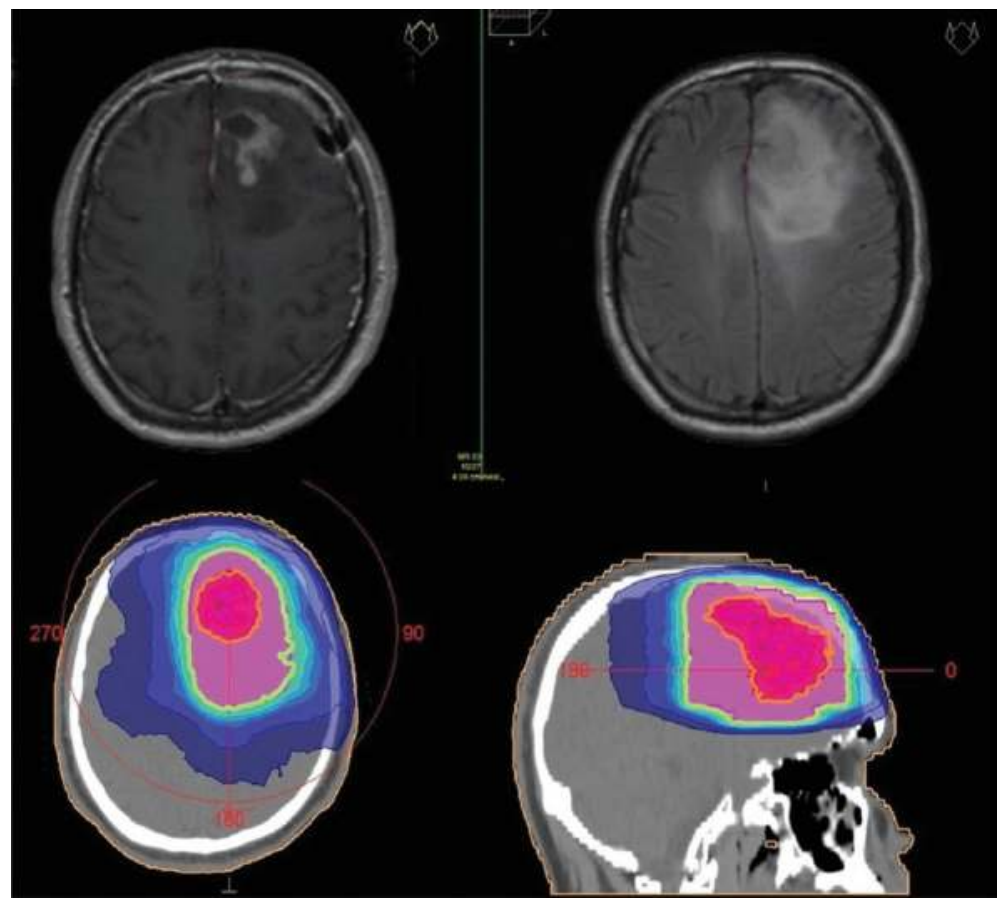

Figure 8. CT after excision of a brain tumor, SIB-IMRT.

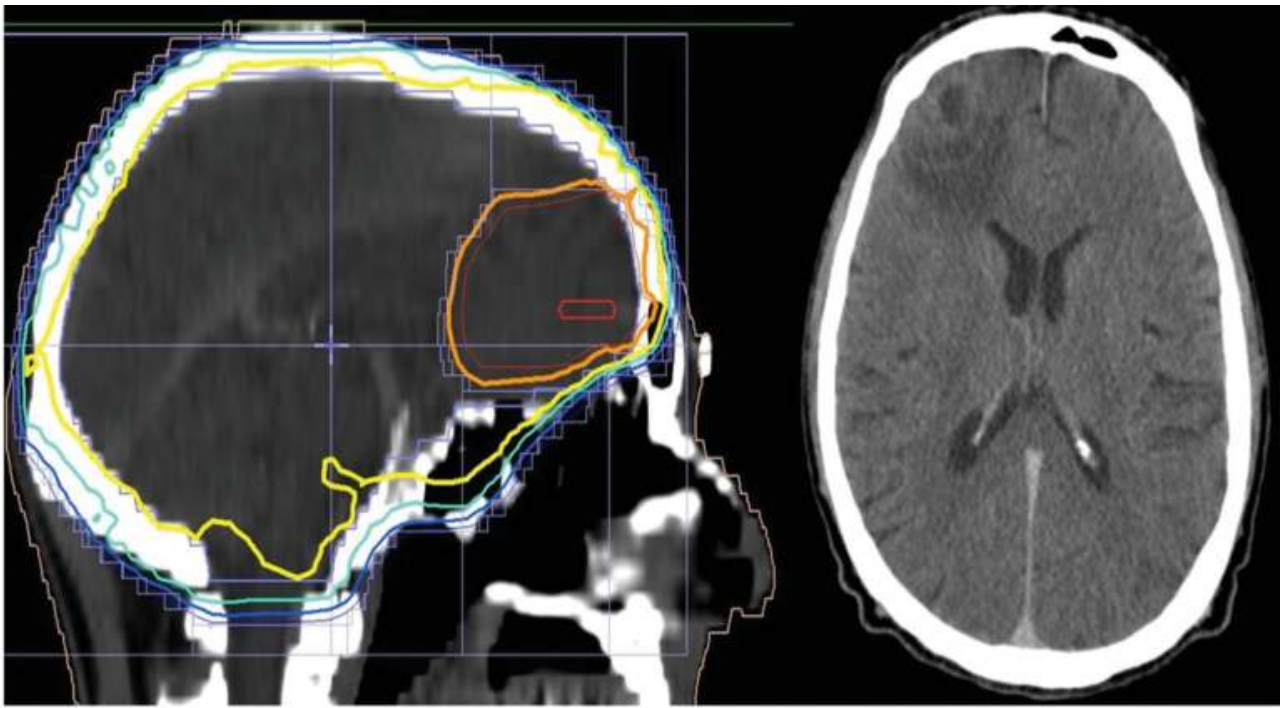

Figure 9. Single brain metastasis treated whole brain VMAT and SAB. 
The true value of radiotherapy confined to the thorax is indisputable in the treatment of locally advanced nonsmall cell lung cancer. However, even with standard chemo-radiation, it is difficult to achieve durable local control, and this contributes to the high morbidity and mortality of patients with NSCLC. Results of RTOG 0617 clinical (Phase III) trial showed that the overall survival of stage III NSCLC patients given a high-dose (74 Gy) conformal radiation therapy with concurrent chemotherapy was no better than that of patients given the standard dose (60 Gy) [44-46]. The new idea is, instead of escalating the dose to the whole PTV, to selectively increase the treatment dose using SIB-IMRT to deliver a higher dose to the GTV and a relatively lower dose to the subclinical disease PTV [47-51].

Clinical outcomes of patients with NSCLC treated with SIB-IMRT have been retrospectively analyzed to evaluate the feasibility of this technology and to provide evidence in support of future clinical studies. The results so far should, at the very least, be considered encouraging (Figure 10).

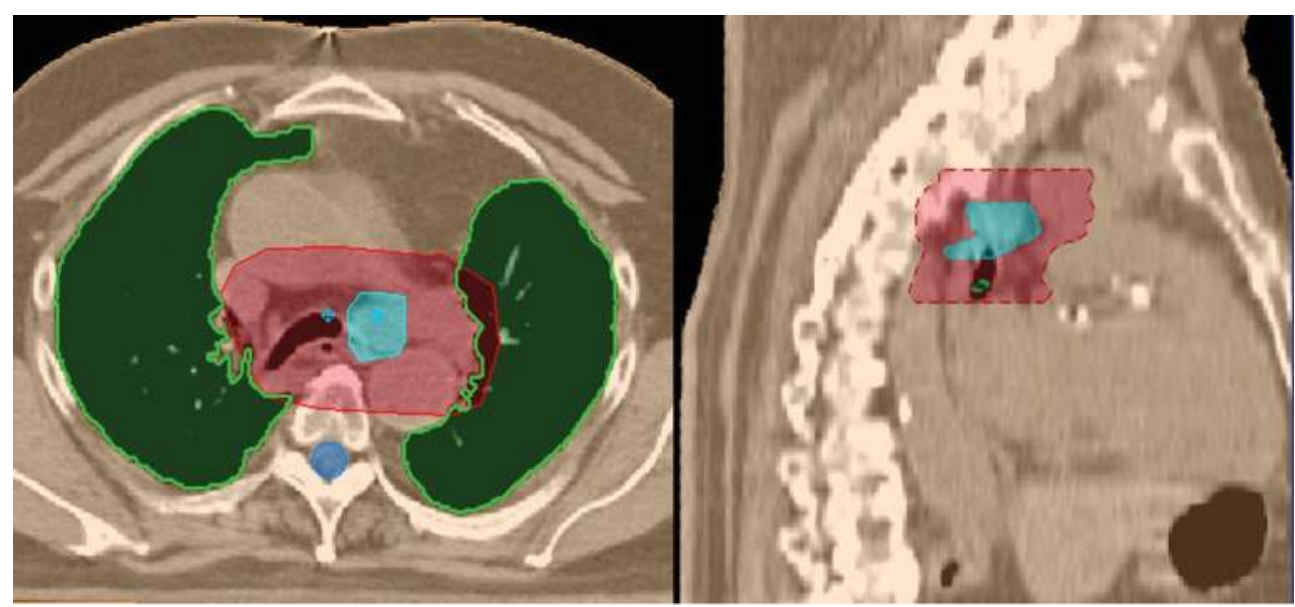

Figure 10. SIB treatment plan in lung cancer nodal recurrence.

Breast-conserving surgery followed by whole breast radiotherapy has become the standard approach for early stage breast cancer since the survival rates have proved to be similar to those with radical surgery. Local control can be improved by an additional boost of 16 Gy to the lumpectomy cavity after administration of $50 \mathrm{~Gy}$ to the whole breast. Breast irradiation with a boost to the tumor bed provides significantly higher local recurrence rates than whole breast irradiation alone, namely, $93.8 \%$ vs. $89.8 \%$ at 10 years. In the EORTC study 22881-10882, the absolute benefit of a boost in terms of local control was most pronounced in young patients [52-55].

A new technical perspective is to apply SIB to the whole breast 3D-CRT plan, in one integrated treatment schedule throughout the entire course of treatment. In this case, the whole breast represents the PTV and is exposed to a daily fraction of 1.8 Gy for 28 days, a total dose of 50, 
40 Gy. Additionally, the tumor bed CTV is delineated, guided by the presence of the surgical clips, hematoma, seroma and/or other surgery-induced changes and is irradiated with a daily dose of $2.3 \mathrm{~Gy}(76.2 \%)$ or $2.4 \mathrm{~Gy}(23.8 \%)$ adding up to a total dose of $64.4 \mathrm{~Gy}$ or $67.2 \mathrm{~Gy}$. These fractionation schemes are biologically equivalent to the sequential boost technique [56, 57].

The SIB technique is proposed for standard use in breast-conserving radiation therapy, because it can be easily implemented to reduce excess volumes of normal tissue irradiated, shorten the treatment course, decrease the dose per fraction for the breast, and increase the dose per fraction for the boost, with a relatively low incidence of acute skin toxicity (Figure 11).

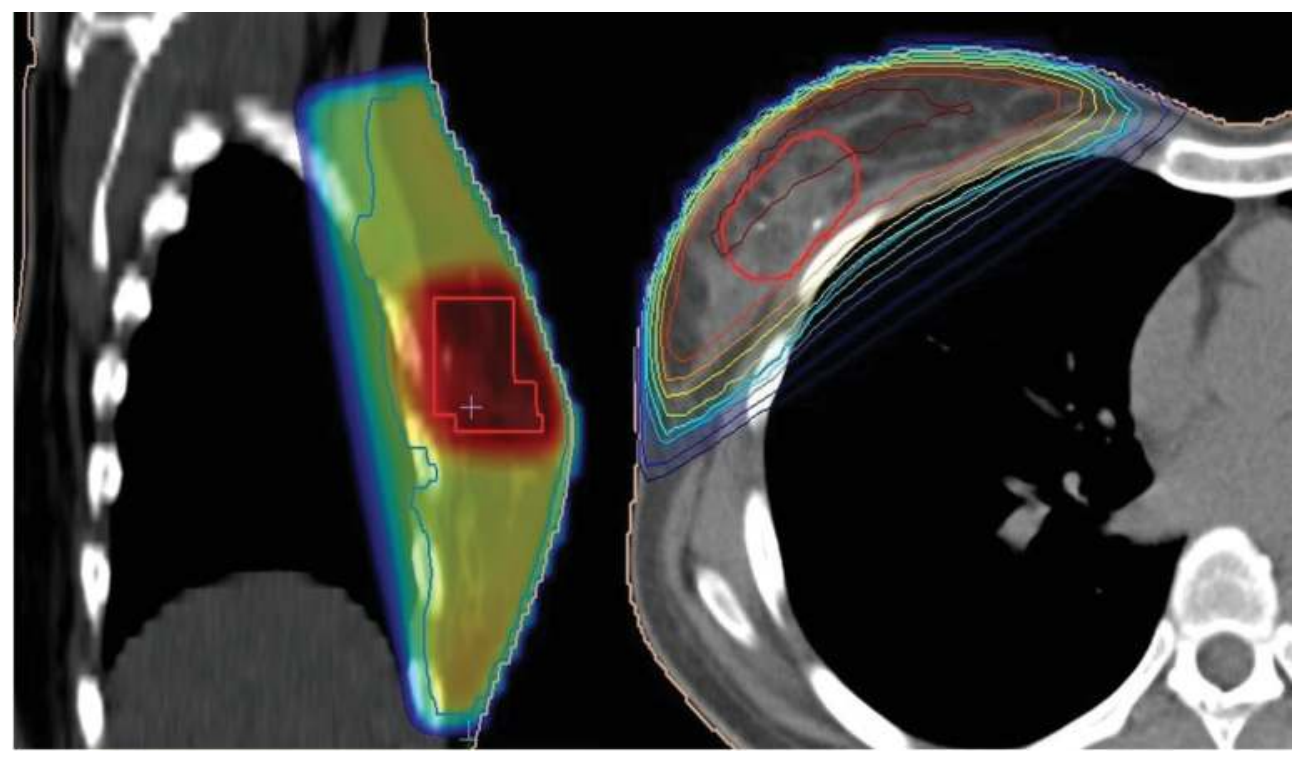

Figure 11. SIB breast cancer-tumor bed guided by the presence of the surgical clips.

The prospective RTOG 0529 phase II trial investigated the utility of IMRT in anal cancer. The twoyear loco-regional control rate was $80 \%$. In comparison with the results of RTOG 98-11, the use of IMRT reduced early G3 or higher gastrointestinal toxicity from 36 to 22\%, and G3 or higher skin toxicity from 47 to $20 \%$. However, until long-term control rates become available, concerns remain regarding potential compromise of tumor control rates using more conformal radiotherapy.

Several different SIB-IMRT schedules are described in various literatures. In the RTOG trial, the total dose varied according to T stage, in which $45 \mathrm{~Gy} / 50.4 \mathrm{~Gy}$ was given to T1/T2 and 55-59 Gy/54 Gy to T3/4 tumors (RTOG 98-11, RTOG 0529). In contrast to tactics used in many US centers, where 59 Gy were administered regardless of $\mathrm{T}$ stage, with very few exceptions for very small primary tumors [58-62].

A new SIB-IMRT schedule is presented to treat patients with anal cancer in two series using moderate single doses from 1.5 to 2.0 Gy with a total dose of 59 Gy in combination with 
mitomycin and 5FU 5FU/MMC. The results, in terms of loco-regional control and toxicity, are comparable to the results of other studies. Remarkably, the incidence of treatment interruptions was very low. Therefore, this regimen appears to be safe and favorable for clinical use.

The optimal technique of IMRT with or without SIB is still under debate, and up to date no standard SIB-IMRT schedule has been established.

The overall radiation therapy treatment time plays an important role, since every single one day prolongation of treatment beyond 30 days leads to $1 \%$ loss of tumor control in patients with cervix carcinoma. The presence of lymph node metastases in cervical cancer patients is a significant risk factor for disease recurrence. Currently available data showed that ${ }^{18} \mathrm{FDG}$-PET $\backslash$ $\mathrm{CT}$ detects more favorable results as far as regional disease when compared with the CT or MRI. PET/CT contributes to better disease control as far as better diagnosis of local and regional disease spread with consequent better delineation based on molecular data [63-66].

IMRT with simultaneous integrated boost (SIB) improves the therapeutic ratio and delivers different doses to different parts of the irradiated volume through dose painting. Further trials are needed in order to optimize the treatment procedure (Figure 12).

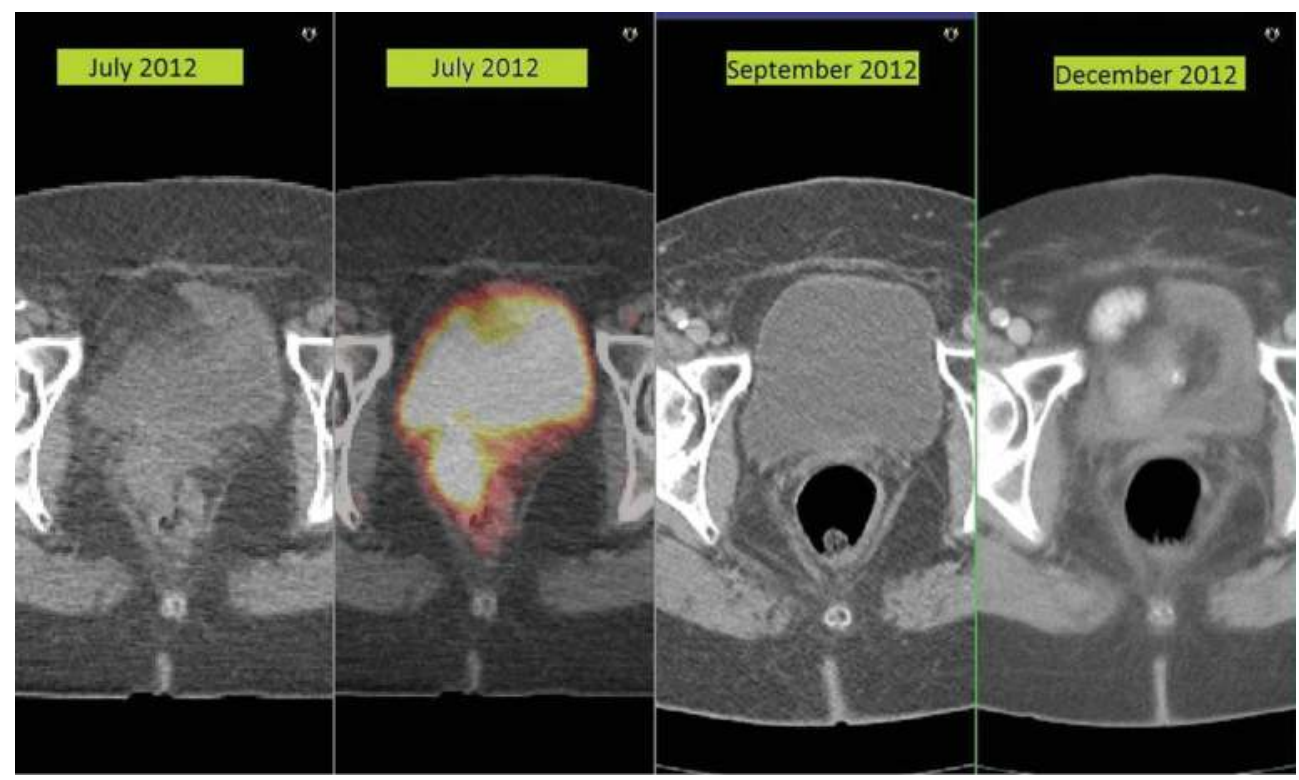

Figure 12. Follow-up of a patient treated with SIB-IMRT.

Local recurrences after external beam radiotherapy for prostate cancer are dose-dependent and mainly occur in the dominant intraprostatic lesion, i.e., the initial tumor site. Trials published demonstrated the feasibility and safety of delivering a SIB to the dominant intraprostatic lesion. No increase in acute and late GU or rectal toxicity was observed when performing a SIB up to an eight-year follow-up. The impact on outcome of focal boosting to the dominant 
intraprostatic lesion is currently evaluated in an ongoing phase 3 trial randomizing intermediate and high-risk prostate cancer patients to receive either $77 \mathrm{~Gy}$ (35 fractions) or 77 Gy to the prostate with an additional boost to the macroscopic tumor up to 95 Gy [67-71].

\section{Conclusion}

The SIB-IMRT or SMART is feasible and time sparing with encouraging loco-regional results and controlled side effects. From a radiobiological point of view, it appears to be an effective RT strategy for the primary treatment of H\&N cancers, and also for various other cancer types. Many different SIB schedules have been employed so far, but a standard regimen has not yet been defined. Based on the available published studies on the SIB-IMRT, the short-term clinical outcome is very promising. However, very few data on late effects are available as of yet, due to the short follow-up time in the majority of the reported studies. However, further data are awaited shortly from ongoing clinical trials in order to determine the most efficient protocol.

For the past 5 years, our department has been using the SIB method where it is applicable. All images shown in this chapter are actual images of patients we personally have treated.

\section{Acknowledgements}

To our medical physicist, radiologist and nurses without whose assistance none of this would have been possible. We are privileged to have our devoted, attentive, not to mention excellently trained personnel as well as the state-of-the-art technological equipment our facilities have to offer, at our disposal.

\section{Conflicts of interest statement}

Nothing to declare.

\section{Author details}

Despina Katsochi

Address all correspondence to: dkatsochi@aktinotherapeia.com

Hygeia Hospital, Athens, Greece

\section{References}

[1] Brahme A. Design principles and clinical possibilities with a new generation of radiation therapy equipment. A review. Acta Oncol. 1987;26:403. 
[2] Bortfeld T, Bürkelbach J, Boesecke R, Schlegel W. Methods of image reconstruction from projections applied to conformation radiotherapy. Phys Med Biol. 1990;35:1423.

[3] Guerrero Urbano MT, Nutting CM. Clinical use of intensity-modulated radiotherapy: Part I. Br J Radiol. 2004;77:88. DOI:10.1259/bjr/54028034

[4] Scorsetti M, Fogliata A, Castiglioni S. Early clinical experience with volumetric modulated arc therapy in head and neck cancer patients. Radiat Oncol. 2010;5:93. DOI:10.1186/1748-717X-5-93

[5] Stützel J, Oelfke U, Nill S. Linac integrated kV-cone beam CT: Technical features and first applications. Med Dosim. 2006;31:62-70. DOI:10.1016/j.meddos.2005.12.008

[6] Dandekar V, Morgan T, Turian J. Patterns-of-failure after helical tomotherapy-based chemoradiotherapy for head and neck cancer: Implications for CTV margin, elective nodal dose and bilateral parotid sparing. Oral Oncol. 2014;50:520-526. DOI:10.1016/j. oraloncology.2014.02.009

[7] Lauve A, Morris M, Schmidt-Ullrich R. Simultaneous integrated boost intensity-modulated radiotherapy for locally advanced head-and-neck squamous cell carcinomas: II-clinical results. Int J Radiat Oncol Biol Phys. 2004;60:374-387.

[8] Bourhis J, Overgaard J, Audry H. Hyperfractionated or accelerated radiotherapy in head and neck cancer:A meta-analysis. Lancet. 2006;368:843.DOI:10.1016/S0140-6736(06)69121-6

[9] Marks LB, Yorke ED, Jackson A. Use of normal tissue complication probability models in the clinic. Int J Radiat Oncol Biol Phys. 2010;376:S10-S976. DOI:10.1016/j. ijrobp.2009.07.1754

[10] Schäfer M, Münter M, Sterzing F, Häring P, Rhein B, Debus J. Measurements of characteristics of time pattern in dose delivery in step-and-shoot IMRT. Strahlenther Onkol. 2005;181:587. DOI:10.1007/s00066-005-1289-7

[11] Grégoire V, Haustermans K, Geets X, Roels S, Lonneux M. PET-based treatment planning in radiotherapy: A new standard? J Nucl Med. 2007;48:68S-77S.

[12] Garden AS, Morrison WH, Wong PF, Tung SS, Rosenthal DI, Dong L, Mason B, Perkins $\mathrm{GH}$, Ang KK. Disease-control rates following intensity-modulated radiation therapy for small primary oropharyngeal carcinoma. Int J Radiat Oncol Biol Phys. 2007;67:438. DOI:10.1016/j.ijrobp.2006.08.078

[13] Morin O, Gillis A, Chen J, Aubin M, Bucci K, Roach M, Pouliot J. Megavoltage conebeam CT: System description and clinical applications. Med Dosim. 2006;31:51-61. DOI:10.1016/j.meddos.2005.12.009

[14] Mac Manus M, Hicks RJ, Everitt S. Role of PET-CT in the optimization of thoracic radiotherapy. J Thorac Oncol. 2006;1(1):81-84. DOI:org/10.1016/S1556-0864(15)31519-7

[15] Hicks RJ, Kalff V, MacManus MP, Ware RE, Hogg A, McKenzie AF, Matthews JP, Ball DL. PET provides high-impact and powerful prognostic stratification in staging newly diagnosed non-small cell lung cancer. J Nucl Med. 2001 Nov;42(11):1596-604 
[16] Menzel HG. The International Commission on Radiation Units and Measurements (ICRU), since its inception in 1925, has had as its principal. J ICRU. 2010;10:83. DOI:10. 1016/j.ijrobp. 2009.07.1754

[17] Marks LB, Yorke ED, Jackson A. Use of normal tissue complication probability models in the clinic. Int J Radiat Oncol Biol Phys. 2010;76:S10-S19. DOI:10.1016/j.ijrobp.2004.04.013

[18] Rengan R, Rosenzweig KE, Venkatraman E, Koutcher LA, Fox JL, Nayak R, Amols H, Yorke E, Jackson A, Ling CC, Leibel SA. Improved local control with higher doses of radiation in large-volume stage III non-small-cell lung cancer. Int J Radiat Oncol Biol Phys. 2004;60(3):741-747.

[19] Dogan N, King S, Emami B, Mohideen N, Mirkovic N, Leybovich LB, Sethi A. Assessment of different IMRT boost delivery methods on target coverage and normal-tissue sparing. Int J Radiat Oncol Biol Phys. 2003;57:1480-1491.

[20] Fu KK, Pajak TF, Trotti A. A Radiation Therapy Oncology Group (RTOG) phase III randomized study to compare hyperfractionation and two variants of accelerated fractionation to standard fractionation radiotherapy for head and neck squamous cell carcinomas: First report of RTOG 9003. Int J Radiat Oncol Biol Phys. 2000;48:7. DOI:10.1016/j. ijrobp.2004.03.010

[21] Butler EB, Teh BS, Grant WH, Woo S. Smart (simultaneous modulated accelerated radiation therapy) boost: a new accelerated fractionation schedule for the treatment of head and neck cancer with intensity modulated radiotherapy - What is the price for speeding? Int J Rad Oncol Biol Phy. 1999;45(1):21-32. DOI: 10.1016/S1470-2045(11)70346-1

[22] Mohan R, Wu Q, Manning M, Schmidt-Ullrich R. Radiobiological considerations in the design of fractionation strategies for intensity-modulated radiation therapy of head and neck cancers. Int J Radiat Oncol Biol Phys. 2000;46:619.

[23] Bourhis J, Sire C, Graff P. Concomitant chemoradiotherapy versus acceleration of radiotherapy with or without concomitant chemotherapy in locally advanced head and neck carcinoma (GORTEC 99-02): An open-label phase 3 randomised trial. Lancet Oncol. 2012;13:145.

[24] Denis F, Garaud P, Bardet E. Final results of the 94-01 French Head and Neck Oncology and Radiotherapy Group randomized trial comparing radiotherapy alone with concomitant radiochemotherapy in advanced-stage oropharynx carcinoma. J Clin Oncol. 2004;22:69.

[25] Marcial VA, Pajak TF, Chang C. Hyperfractionated photon radiation therapy in the treatment of advanced squamous cell carcinoma of the oral cavity, pharynx, larynx, and sinuses, using radiation therapy as the only planned modality: (preliminary report) by the Radiation Therapy Oncology Group (RTOG). Int J Radiat Oncol Biol Phys. 1987;13:41.

[26] Beck-Bornholdt HP, Dubben HH, Liertz-Petersen C, Willers H. Hyperfractionation: Where do we stand? Radiother Oncol. 1997;43:1. 
[27] Eisbruch A, Harris J, Garden AS. Multi-institutional trial of accelerated hypofractionated intensity-modulated radiation therapy for early-stage oropharyngeal cancer (RTOG 00-22). Int J Radiat Oncol Biol Phys. 2010;76:1333-1338. DOI:10.1016/j.ijrobp.2009.04.011

[28] Songthong AP, Kannarunimit D, Chakkabat C. A randomized phase II/III study of adverse events between sequential (SEQ) versus simultaneous integrated boost (SIB) intensity modulated radiation therapy (IMRT) in nasopharyngeal carcinoma; preliminary result on acute adverse events. Radiat Oncol. 2015;10:166. DOI:10.1186/s13014-015-0472-y

[29] Koom WS, Kim TH, Shin KH, Pyo HR, Kim JY, Kim DY, Yoon M, Park SY, Lee DH, Ryu JS, Jung YS, Lee SH, Cho KH. Smart (Simultaneous Modulated Accelerated Radiotherapy) for locally advanced nasopharyngeal carcinomas. Head Neck. 2008;10:159-169. DOI:10. 1002/hed.20667

[30] Nguyen-Tan PF, Zhang Q, Ang KK. Randomized phase III trial to test accelerated versus standard fractionation in combination with concurrent cisplatin for head and neck carcinomas in the Radiation Therapy Oncology Group 0129 trial: Long-term report of efficacy and toxicity. J Clin Oncol. 2014;32:3858. DOI:10.1200/JCO.2014.55.3925

[31] Beitler JJ, Zhang Q, Fu KK, Trotti A, Spencer SA, Jones CU, Garden AS, Shenouda G, Harris J, Ang KK. Final results of local-regional control and late toxicity of rtog 9003: A randomized trial of altered fractionation radiation for locally advanced head and neck cancer. Int J Radiat Oncol Biol Phys. 2014;89:13-20. DOI:10.1016/j.ijrobp.2013.12.027

[32] Xiao C, Hanlon A, Zhang Q. Risk factors for clinician-reported symptom clusters in patients with advanced head and neck cancer in a phase 3 randomized clinical trial: RTOG 0129. Cancer. 2014;120:848. DOI:10.1002/cncr.28500

[33] Stupp R, Mason WP, van den Bent MJ, Weller M, Fisher B, Taphoorn MJ. Radiotherapy plus concomitant and adjuvant temozolomide for glioblastoma. N Engl J Med. 2005;352: 987-996. DOI:10.1056/NEJMoa043330

[34] Farzin M, Molls M, Astner S, Rondak IC, Oechsner M. Simultaneous integrated vs. sequential boost in VMAT radiotherapy of high-grade gliomas. Strahlenther Onkol. 2015;191:945-952. DOI: 10.1056/NEJMoa043330

[35] Sultanem K, Patrocinio H, Lambert C, Corns R, Leblanc R, Parker W. The use of hypofractionated intensity-modulated irradiation in the treatment of glioblastoma multiforme: Preliminary results of a prospective trial. Int J Radiat Oncol Biol Phys. 2004;58:247-252.

[36] Monjazeb AM, Ayala D, Jensen C, Case LD, Bourland JD, Ellis TL. A phase I dose escalation study of hypofractionated IMRT field-in-field boost for newly diagnosed glioblastoma multiforme. Int J Radiat Oncol Biol Phys. 2012;82:743-748. DOI:10.1016/j. ijrobp.2010.10.018

[37] Truc G, Bernier V, Mirjolet C, Dalban C, Mazoyer F, Bonnetain F, Blanchard N, Lagneau É, Maingon P, Noël G. A phase I dose escalation study using simultaneous integratedboost IMRT with temozolomide in patients with unifocal glioblastoma. Cancer/ Radiothérapie. 2016:20;193-198. DOI:10.1016/j.canrad.2015.12.005 
[38] Giaj N, Gianluisa L, Alba S, Sergio F, Ricchetti F, Mazzola R, Naccarato S, Ruggieri R, Filippo A. Whole brain radiotherapy with hippocampal avoidance and simultaneous integrated boost for brain metastases: A dosimetric volumetric-modulated arc therapy study. Radiol Med. 2016;121:60-69. DOI:10.1007/s11547-015-0563-8.

[39] Mehta MP, Tsao MN, Whelan TJ, Morris DE, Hayman JA, Flickinger JC, Mills M, Rogers $\mathrm{CL}$, Souhami L. The American society for therapeutic radiology and oncology (ASTRO) evidence based review of the role of radiosurgery for brain metastasis. Int J Radiat Oncol Biol Phys. 2005;63:37-46. DOI:10.1016/j.ijrobp.2005.05.023.

[40] Kondziolka D, Patel A, Lunsford LD, Kassam A, Flickinger JC. Stereotactic radiosurgery plus whole brain radiotherapy versus radiotherapy alone for patients with multiple brain metastases. Int J Radiat Oncol Biol Phys. 1999;45:427-434.

[41] Andrews DW, Scott CB, Sperduto PW. Whole-brain radiation therapy with or without stereotactic radiosurgery boost for patients with one to three brain metastases: Phase III results of the RTOG-9508 randomized trial. Lancet. 2004;363:1665-1672. DOI:10.1016/ S0140-6736(04)16250-8

[42] Prokic V, Wiedenmann N, Fels F, Schmucker M, Nieder C, Grosu AL. Whole brain irradiation with hippocampal sparing and dose escalation on multiple brain metastases: A planning study on treatment concepts. Int J Radiat Oncol Biol Phys. 2013;85:264-270. DOI:10.1016/j.ijrobp.2012.02.036

[43] Lagerwaard FJ, van der Hoorn EA, Verbakel WF, Haasbeek CJ, Slotman BJ, Senan S. Whole-brain radiotherapy with simultaneous integrated boost to multiple brain metastases using volumetric modulated arc therapy. Int J Radiat Oncol Biol Phys. 2009;75:253259. DOI:10.1016/j.ijrobp.2009.03.029

[44] Barraclough LH, Swindell R, Livsey JE, Hunter RD, Davidson SE. External beam boost for cancer of the cervix uteri when intracavitary therapy cannot be performed. Int J Radiat Oncol Biol Phys. 2008;71:772-778. DOI:10.1016/j.ijrobp.2007.10.066

[45] Van de Bunt L, Jurgenliemk-Schulz IM, de Kort GA, Roesink JM, Tersteeg RJ, van der Heide UA. Motion and deformation of the target volumes during IMRT for cervical cancer: What margins do we need? Radiother Oncol. 2008;88:233-240. DOI:10.1016/j.radonc.2007.12.017

[46] Kaatee RS, Olofsen MJ, Verstraate MB, Quint S, Heijmen BJ: Detection of organ movement in cervix cancer patients using a fluoroscopic electronic portal imaging device and radiopaque markers. Int J Radiat Oncol Biol Phys. 2002;54:576-583.

[47] Van Baardwijk A, Wanders S, Boersma L. Mature results of an individualized radiation dose prescription study based on normal tissue constraints in stages I to III non-smallcell lung cancer. J Clin Oncol. 2010;28:1380-1386. DOI:10.1200/JCO.2009.24.7221

[48] Bradley JD, Paulus R, Komaki R. Standard-dose versus high-dose conformal radiotherapy with concurrent and consolidation carboplatin plus paclitaxel with or without cetuximab for patients with stage IIIA or IIIB non-small-cell lung cancer (RTOG 0617): A randomised, two-by-two factorial phase 3 study. Lancet Oncol. 2015;16:187-199. 
[49] Vera P, Bohn P, Edet-Sanson A. Simultaneous positron emission tomography (PET) assessment of metabolism with (18)F-fluoro-2-deoxy-d-glucose (FDG), proliferation with (18)F-fluoro-thymidine (FLT), and hypoxia with (18)fluoro-misonidazole (F-miso) before and during radiotherapy in patients with non-small-cell lung cancer (NSCLC): A pilot study. Radiother Oncol. 2011;98:109-116. DOI:10.1016/j.radonc.2010.10.011

[50] Even AJG, van der Stoep J, Zegers CML, Reymen B, Troost EGC, Lambin P, van Elmpt W. PET-based dose painting in non-small cell lung cancer: Comparing uniform dose escalation with boosting hypoxic and metabolically active sub-volumes. Radiother Oncol. 2015;116(2):281-286. DOI:10.1016/j.radonc.2015.07.013.

[51] Han D, Qin Q, Hao S, Huang W, Wei Y, Zhang Z, Wang Z, Li B. Feasibility and efficacy of simultaneous integrated boost intensity-modulated radiation therapy in patients with limited-disease small cell lung cancer. Radiat Oncol. 2014;11(9):280. DOI:10.1186/ s13014-014-0280-9.

[52] Bartelink H, Horiot JC, Poortmans PM, Struikmans H, Van den Bogaert W, Fourquet A. Impact of a higher radiation dose on local control and survival in breast-conserving therapy of early breast cancer: 10 -year results of the randomized boost versus no boost EORTC 22881-10882 trial. J Clin Oncol. 2007;25:3259-3265. DOI:10.1200/JCO.2007.11.4991.

[53] Bentzen SM, Agrawal RK, Aird EG, Barrett JM, Barrett-Lee PJ, Bliss JM. The UK Standardisation of Breast Radiotherapy (START) Trial A of radiotherapy hypofractionation for treatment of early breast cancer: A randomised trial. Lancet Oncol. 2008;9:331341. DOI:10.1016/S1470-2045(08)70077-9

[54] Dellas K, Vonthein R, Zimmer J, Dinges S, Boicev AD, Andreas P. Hypofractionation with simultaneous integrated boost for early breast cancer: Results of the German multicenter phase II trial (ARO-2010-01). Strahlenther Onkol. 2014;190:646-653. DOI:10.1007/ s00066-014-0658-5

[55] Sedlmayer F, Sautter-Bihl ML, Budach W, Dunst J, Fastner G, Feyer P. DEGRO practical guidelines: Radiotherapy of breast cancer I: Radiotherapy following breast conserving therapy for invasive breast cancer. Strahlenther Onkol. 2013;189:825-833. DOI:10.1007/ s00066-013-0437-8

[56] Alford SL, Prassas GN, Vogelesang CR, Leggett HJ, Hamilton CS. Adjuvant breast radiotherapy using a simultaneous integrated boost: Clinical and dosimetric perspectives. J Med Imaging Radiat Oncol. 2013;57:222-229. DOI:10.1111/j.1754-9485.2012.02473.x

[57] Bantema-Joppe EJ, Schilstra C, de Bock GH, Dolsma WV, Busz DM, Langendijk JA. Simultaneous integrated boost irradiation after breast-conserving surgery: Physicianrated toxicity and cosmetic outcome at 30 months' follow-up. Int J Radiat Oncol Biol Phys. 2012;83:e471-e477. DOI:10.1016/j.ijrobp.2012.01.050

[58] Hsu A, Hara W, Pawlicki J. IMRT in the treatment of anal cancer: A dosimetric comparison of conventional 3D, IMRT, and IMRT with integrated boost. Proc Am Soc Ther Radiol Oncol. 2006;66:674. 
[59] Ajani JA, Winter KA, Gunderson LL. Intergroup RTOG 98-11: A phase III randomized study of 5-fluorouracil (5-FU), mitomycin, and radiotherapy versus 5-fluorouracil, cisplatin and radiotherapy in carcinoma of the anal canal. Proc Am Soc Clin Oncol. 2012;26:18. DOI:10.1200/JCO.2012.43.8085

[60] Chen YJ, Liu A, Tsai PT, Vora NL, Pezner RD, Schultheiss TE, Wong JY. Organ sparing by conformal avoidance intensity-modulated radiation therapy for anal cancer: Dosimetric evaluation of coverage of pelvis and inguinal/femoral nodes. Int J Radiat Oncol Biol Phys. 2005;63:274-281. DOI:10.1016/j.ijrobp.2005.05.052

[61] Kachnic LA1, Winter K, Myerson RJ, Goodyear MD, Willins J. Esthappan J, Haddock MG, Rotman M, Parikh PJ, Safran H, Willett CG. Radiation Therapy Oncology Group (RTOG). A Phase II Evaluation of Dose-Painted IMRT in Combination with 5-Fluorouracil and Mitomycin-C for Reduction of Acute Morbidity in Carcinoma of the Anal Canal, RTOG 05-29. RTOG, Philadelphia, PA. 2012. Int J Radiat Oncol Biol Phys. 2013 May 1;86(1):27-33. DOI:10.1016/j.ijrobp.2012.09.023

[62] Jani AB, Farrey KJ, Rash C, Heimann R, Chmura SJ, Milano MT. Intensity-modulated radiation therapy (IMRT) in the treatment of anal cancer: toxicity and clinical outcome. Int J Radiat Oncol Biol Phys. 2005;63:354-361. DOI:10.1016/j.ijrobp.2005.02.030

[63] Georg D, Kirisits C, Hillbrand M, Dimopoulos J, Potter R. Image-guided radiotherapy for cervix cancer: High-tech external beam therapy versus high-tech brachytherapy. Int J Radiat Oncol Biol Phys. 2008;71:1272-1278. DOI:10.1016/j.ijrobp.2008.03.032

[64] Lim K, Small W Jr, Portelance L, Creutzberg C, Jurgenliemk-Schulz IM, Mundt A, Mell LK, Mayr N, Viswanathan A, Jhingran A. Consensus guidelines for delineation of clinical target volume for intensity-modulated pelvic radiotherapy for the definitive treatment of cervix cancer. Int J Radiat Oncol Biol Phys. 2011;79:348-355. DOI:10.1016/j. ijrobp.2009.10.075

[65] Fyles A, Keane TJ, Barton M, Simm J. The effect of treatment duration in the local control of cervix cancer. Radiother Oncol. 1992;25:273-279.

[66] Molla M, Escude L, Mouet P, Popowski Y, Hidalgo A, Rouzaud M, Linero D, Miralbell R. Fractionated stereotactic radiotherapy boost for gynecologic tumors: An alternative to brachytherapy? Int J Radiat Oncol Biol Phys. 2005 May 1;62(1):118-24. DOI:10.1016/j. ijrobp. 2004.09.028

[67] Zelefsky MJ, Pei X, Chou JF, Schechter M, Kollmeier M, Cox B. Dose escalation for prostate cancer radiotherapy: Predictors of long-term biochemical tumor control and distant metastases-free survival outcomes. Eur Urol. 2011;60:1133-1139. DOI:10.1016/j. eururo.2011.08.029

[68] Fonteyne V, Villeirs G, Speleers B, De Neve W, De Wagter C, Lumen N. Intensitymodulated radiotherapy as primary therapy for prostate cancer: Report on acute toxicity after dose escalation with simultaneous integrated boost to intraprostatic lesion. Int J Radiat Oncol Biol Phys. 2008;72:799-807. DOI:10.1016/j.ijrobp.2008.01.040 
[69] Ippolito E, Mantini G, Morganti AG, Mazzeo E, Padula GD, Digesu C. Intensitymodulated radiotherapy with simultaneous integrated boost to dominant intraprostatic lesion: Preliminary report on toxicity. Am J Clin Oncol. 2012;35:158-162. DOI:10.1097/ COC.0b013e318209cd8f

[70] Lips IM, van der Heide UA, Haustermans K, van Lin EN, Pos F, Franken SP. Single blind randomized phase III trial to investigate the benefit of a focal lesion ablative microboost in prostate cancer (FLAME-trial): Study protocol for a randomized controlled trial. Trials. 2011;12:255. DOI:10.1186/1745-6215-12-255

[71] Cox JD, Stetz J, Pajak TF. Toxicity criteria of the Radiation Therapy Oncology Group (RTOG) and the European Organization for Research and Treatment of Cancer (EORTC). Int Radiat Oncol Biol Phys. 1995;31:1341-1346. DOI:10.1016/0360-3016(95)00060-C. 
